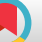

\title{
Designing, Developing, and Evaluation of a Germane Load-Based Cognitive Rehabilitation Program for Students with Specific Learning Disabilities
}

\author{
Maryam Kaboli ${ }^{1}$, Parvin Kadivar ${ }^{2,{ }^{*}}$, Mohammad Hossein Abdollahi ${ }^{2}$ and mehdi Arabzadeh ${ }^{2}$ \\ ${ }^{1}$ Kharazmi University ,Tehran ,Iran \\ ${ }^{2}$ Department of Education and Psychology, Kharazmi University, Tehran, Iran \\ "Corresponding author: Department of Education and Psychology, Kharazmi University, Tehran, Iran. Email: kadivar220@yahoo.com
}

Received 2020 November 17; Accepted 2020 December 18

\begin{abstract}
Objectives: The current study aimed to design, develop, and evaluate a germane load-based cognitive rehabilitation program designed for students with special learning disabilities.

Methods: The exploratory, descriptive method was used for designing the program. Thematic analysis (Sterling (2001)) was used to estimate the germane load themes. Based on the previous studies, 85 specific germane load codes were identified and evaluated. According to the results, the Multimedia Principle in germane load, Multi-personalization principle, and the Feedback principle consisted of 16, 17, 12 basic themes, respectively. Besides, the Reflection principle, as the most important learning principle in germane load, contained 17 basic themes, and the Guided Activity principle consisted of 8 basic themes. The content validity method was used to validate the program, both quantitatively and qualitatively, with a panel of 10 experts as well as two relative content validity coefficients (CVR) and content validity index (CVI).

Results: The minimum and maximum content validity index (CVI) for each article or program component are 0.8 and 1 , respectively, and the minimum and maximum content validity index (CVR) for each article or program component are 0.7 and 1 , respectively. Conclusions: The results showed that the germane load-based cognitive rehabilitation program for students with special learning disabilities has appropriate content validity as well as the necessary validity for educational, clinical, and research purposes.
\end{abstract}

\section{Background}

The special learning disorder is a major neurodevelopmental disorder that mostly occurs in childhood (1). They mostly suffer from problems in written expression, reading, and mathematics (2). A large number of learners with learning disorders have difficulty in learning the course materials because of learning disabilities. While their intelligence score is usually higher than average, under nearly similar educational situations, their performance is weaker than learners (3). Meanwhile, even in a proper educational context, they are not able to learn in certain areas, even those who do not have clear biological lesions, in the absence of strong social and psychological problems, and those who have moderate intelligence. The consequence of the big distinction between the level of ability and performance is that these students, despite having intelligence abilities, do not benefit from the proper cognitive functions (1). Individuals with learning disabilities also have a lower cognitive load capacity of working memory; for example, the Fifth diagnostic and statistical manual of mental disorders (DSM-5) in describing a specific learning disability in one of the axes stated that there are learning disabilities in preschool age, but because the processing demands of the child are limited, they do not become apparent (that is, the disorder becomes apparent when a person has to take speed-related assignments and tests, or when he or she has to complete homework for a limited time, or when he or she has heavy academic responsibilities and tasks assigned to him or her). Therefore, this guide refers to the shortcomings of these people regarding the cognitive load of working memory. Hence, it can be argued that cognitive impairment is a significant feature of children with special learning disabilities (4). Cognitive load theory $(5,6)$ reflects our understanding of human cognitive architecture to make hypotheses in the field of novel teaching approaches. The cognitive load theory intends to explain the way our mind processes information and how a load of educational matters and activities impacts student's ability to process new information and to create knowledge in long-term memory. The basic 
premise of this theory is that human cognitive processing is strongly affected by the limitations of working memory, and hence, we are only able to process a small amount of information over a specific period (7). In 1998, Sweller reviewed cognitive loads and categorized them into three types: Intrinsic, Extraneous, and germane. Intrinsic cognitive load refers to the complexity associated with processing information and is related to the concept of component interaction (7). An extraneous cognitive load is about how information is presented and what the student should do based on the learning process. But the germane load, which is emphasized in the present research, refers to working memory resources that are dedicated to counteracting the intrinsic load instead of the extra cognitive load. In other words, the germane load is the load of engagement in learning activities that leads to the acquisition of organized schemas and their automation. This load is extracted from educational materials that facilitate effective and efficient learning processes. Therefore, it affects learning outcomes (7). Sweller (2020) referred to germane load as germane resources, indicating the amount of working memory capacity associated with learning. Germane cognitive load excludes limited working memory resources from engagement to non-learning activities and only considers resources that are directly related to the overall learning process through intrinsic learning-related information (7). Germane load is about cognitive activities that are intentionally designed to increase schema acquisition and automation. Germane load resources are directed toward cognitive activities specially designed to enhance learning outcomes or improve learner's motivation. Such activities can significantly develop the overall cognitive load. Howsoever, they contribute directly to learning. Therefore, germane load is a cognitive load that directly contributes to schema acquisition. Meanwhile, problems related to cognitive load are common in those suffering from special learning disabilities. Seok and Dacosta (2010) argued that when designing programs to help those with learning disabilities, adhering to cognitive load principles is more important, as memory impairment is much more evident in people with special learning disabilities and is one of their main challenges in educational settings (8). Hence, it can be considered as an effective intervention to improve the cognitive deficits of learners with cognitive rehabilitation learning disabilities. Cognitive rehabilitation, which is used to treat and rehabilitate cognitive disorders, can be used to strengthen damaged areas or to replace new patterns of disorder compensation (9). In fact, cognitive rehabilitation refers to instructions based on the findings of cognitive science that aim to improve cognitive deficits using games, all of which refer to the principle of the brain flexibility (10). The most widely referred definition of cognitive rehabilitation is an interdisciplinary definition approved by the Brain Injury Interdisciplinary Special Interest Group (BI-ISIG): accordingly, cognitive rehabilitation is a set of systematic and functional services of cognitive therapy activities that are based on the assessment and understanding of a person's brainbehavior deficits. Services contain 1) improving, reinforcing, or recreating previous cognitive behavioral patterns; or 2) creating new patterns of cognitive activity or compensatory mechanisms for damaged nervous systems. This description intends to provide comprehensive and interdisciplinary rehabilitation programs with interventions to restore or reorganize lost performance. Cognitive rehabilitation is a systematic and practical set of medical services designed to improve cognitive function and to participate in activities that may be affected by disabilities in one or more cognitive areas (Brain Injury Association of America, 2012). However, in recent decades, many advances have been made in the development of cognitive rehabilitation programs, including the studies conducted by Alloway (2012); Alloway, Bibile, and Lau (2013); Klingberg, Thorell, Lindqvist, Bergman, and Bohlin (2005); Dahlin (2011); Thorell, Lindqvist, Bergman, Bohlin, and Klingberg (2009); Schwaighofer, Bühner, and Fischer (2017). However, the abovementioned training packages and protocols are mainly focused on some particular games, methods, and techniques of cognitive rehabilitation, and none has focused on the principles of cognitive load. Moreover, none of these studies have designed and compiled a standard and systematic educational program based on common educational design patterns. Also, students' cognitive empowerment plays a prominent role in solving the problems of these people, especially students who suffer from cognitive deficits (e.g., students with learning disabilities).

\section{Objectives}

According to what was mentioned before, by designing a cognitive rehabilitation program based on a cognitive approach intended to compensate for the deficiencies of people with special learning disabilities, the current study aimed to fill the aforementioned gap in the literature. Accordingly, the present study aimed to design, formulate, and evaluate an effective cognitive rehabilitation program for students with special learning disabilities, and the following questions were raised: 1 . What are the components or themes of germane load in developing a germane load based on cognitive rehabilitation program? 2. Does the germane load-based cognitive rehabilitation program have content validity? 


\section{Methods}

This research was conducted in two general stages. In the first stage, an exploratory approach, which is a descriptive method, was used to explain the conceptual framework of cognitive rehabilitation based on the germane cognitive load as well as to design and develop an educational-psychological program. This approach is based on obtaining information from various studies related to the research field. To design a program, the following steps should be performed in order: initial protocol (selection of target subgroups, expectations, questions), determination of program goals, selection of theories related to designing concepts and goals, selection of psychological processes related to goal-based research and theories, selection of techniques and tasks to run the operation, evaluation of selected items by external experts, and, last but not least, review and preparation of the final version (11). In the second part of the research, the validity of the designed program was assessed. To achieve this goal, Lawshe (1975) method was used. Since in the present study 10 experts were invited to assess the program, the minimum acceptable value to verify the validity of the components of the program was considered as 0.62 (12).

Waltz and Basel's method (1981; quoted Hussein, sacrifice, and Ibn al-Ahmadi, 2015) was used to calculate the content validity index (CVI). In this method, the minimum acceptable value for the CVI index is 0.79 , and items with a score $<0.79$ should be removed. According to the experts' opinions, the following criteria were selected: "relevance", "clarity", and "simplicity". The Equation (1) was used to calculate the content validity index for each of these criteria (Davis, 1992). In this way, the total CVI for each component or item includes the mean total score of the three criteria.

$C V I=\frac{\text { No. of answers in agreement with the ranks } 3 \text { and } 4}{\text { The total No. of responses to each item }}$

In this method, items with a score $>0.79$ are appropriate, between 0.79 and 0.79 need revision, and scores $<0.70$ are unacceptable and must be deleted (13). To design the program, all books and scientific articles related to cognitive rehabilitation and load germane as well as theories related to this field, were reviewed. It worth noting that theories were selected using a purposive sampling method, while emphasizing maximum diversity or heterogeneity. The review was stopped upon reaching data saturation.

To achieve this goal, Springer, Science Direct, and PubMed databases were searched to identify relevant studies published during the past decade using the keywords of cognitive rehabilitation and germane load. Eventually, 5 books and 32 articles were selected, which had an appropriate study population, sampling methodology, sample size, research tools, and research methodology. In the following, 10 specialists in the field of rehabilitation and education (i.e., cognitive rehabilitation, cognitive load, and e-learning) were selected by purposive sampling.

\subsection{Research Process}

The first step in designing a germane load-based cognitive rehabilitation program is to carefully review the literature. In this step, special attention should be paid to studies on people with learning disabilities and their deficiencies. This step is intended to accurately identify the deficiencies of these individuals concerning memory-based duplication, then responding to the identified deficiencies. In addition, various theories, sources, and researches in the field of germane load and cognitive rehabilitation were studied, and articles related to these fields were reviewed.

In the second step, according to the results of previous research, several goals were defined for the program. In other words, first, the shortcomings of these people in the memory-based cognitive domains were identified, then the goals of the program, which was specifically designed to improve executive function skills, were selected. In addition, the germane load was focused on the goals of long-distance transmission in the rehabilitation program, as well as cognitive load-related problems in people with learning disabilities.

In the third step, the theoretical and research foundations of cognitive rehabilitation and germane load were reviewed. To design and develop a rehabilitation program based on germane load, we tried to investigate rehabilitation programs that were reported in previous studies. This step intended to strengthen executive functions through extracting important information, such as Neuroplasticity, Head Start REDI, Promoting Alternative Thinking Skills (PATHS), The Incredible Years, Scaffolding designed to promote Self-Regulation, SSS Program, Cogmed, Tools of the mind, Jungle Memory, Capitan Log, Memory GYM, Smart Mind, CAN Tab and IVA-2, and ideas.

In the fourth step, according to the psychological processes related to research based on the goals and theories of this field as well as using thematic analysis, several areas were selected. Thus, according to the results of previous research in the field of cognitive rehabilitation and cognitive load, as well as the deficits of people with learning disabilities, interventions were selected. Also, based on studies related to cognitive load. Shay (2014) mentioned germane load as the most important cognitive load. The principles of germane load reinforcement are also discussed in detail (14). In the fifth step, with the help of experts participating in the research and two programmers, the techniques and tasks that make the processes operational were designed 
and coded. In this way, 9 computer tasks with different difficulty, which included about 50 tasks, were considered and designed. As Ovey and Patterson (2014) reported that, games with a puzzle mode were more effective, the tasks were designed in the form of games. Besides, we tried to use topics that are attractive to children and within their comprehension (Table 1).

In the sixth step, the designed assignments that were no longer visible and executable on the computer were evaluated by the experts participating in the study, and the necessary corrections were made so that the program would be more in line with the specific characteristics of children with learning disabilities and their shortcomings in terms of cognitive load would be observed. In addition, the rehabilitation program was reviewed by several experts in this field, and its problems were fixed and their suggestions were followed.

The seventh and final step was dedicated to reviewing and preparing the final form of the program. The purpose of this phase was to implement a preliminary rehabilitation program. Hence, this step only intended to modify the rehabilitation program and adapt it to the characteristics of students with learning disabilities. Moreover, special attention was paid to identifying gaps. For this purpose, a rehabilitation program was performed for 2 - 3 sessions on 5 students ( 3 with special learning disabilities and 2 with normal characteristics) and its problems and shortcomings were identified and addressed. After fixing the problems, the final form was ready to be used for rehabilitation sessions. It worth noting that all homeworks have an educational aspect and the instructor has a guiding role in all stages and scoring students can provide the ground for the student to learn more. The germane load-based cognitive rehabilitation tasks are summarized in the following tables. It should be noted that the assignments are designed based on the five principles of germane load reinforcement.

\section{Results}

To answer the question of "what components or themes of the germane load should be considered when developing a cognitive rehabilitation program?", first, we used the thematic analysis approach proposed by Stirling (2001) to extract themes. Hence, initially, codes were extracted and then categorized into themes. In this regard, special attention was paid to the distinction between themes and their wideness. Therefore, based on what was mentioned before, the organizer themes were determined based on various theories in this field, and the basic themes related to each organizer were categorized. Based on studies from various sources, finally, 85 specific germane load codes were identified and evaluated. Based on the results, the "Multimedia" principle in germane load consisted of 16 basic themes, "Personalization" principle had 17 basic themes, "Feedback" principle had 12 basic themes, "Reflection" principle, as the most important learning principle in germane load, had 17 basic themes, and, finally, the "Guided Activity" principle consisted 8 basic themes (Table 2).

After reviewing and analyzing the results mentioned in the above table, the factors affecting the germane load were identified as follows:

1- Using multimedia: According to this concept, training that employs verbal and visual representations are more likely to lead to meaningful learning and germane load compared to those which only use one of these methods. For example, when verbally teaching different layers of the earth in a Multimedia Principle, it is better to use images as well. The Multimedia Principle is based on the theory of dual codes (15). This theory states that human mental processing includes separate channels for processing visual and verbal materials (16);

2- Personalization: According to this concept, personalized written and spoken verbal messages are more effective in learning. That is, training is presented in a friendly, conversational, and informal way, rather than being formally and informally. The principle of personalization is based on the idea that providing information in an informal and conversational manner promotes the active processing of new information by relating content to the student's own experiences, which in turn results in creating a deeper memory of the learning experience (5);

3- Feedback: According to this concept, giving feedback to learners leads to cognitive processing, which is necessary for a deeper understanding. In fact, according to cognitive learning theory, the effectiveness of the educational Multimedia Principle depends on the relationship between the amount of feedback system and learners' prior knowledge. In other words, feedback during training encourages necessary and reproductive processing by directing learners' attention and organizing new information (15);

4- Thinking: This component is at the heart of the reproductive processing hypothesis. It encourages students to provide explanations or images based on the principle of thinking, which leads to organizing and integrating new information with learners' prior knowledge. In other words, it challenges learners to organize the steps related to the causal chain of events and makes them think in an interactive educational program, which in turn deepen their learning (17);

5- Guided Activity: Guided Activity occurs when learners can interact in learning environments and receive guid- 


\begin{tabular}{|c|c|}
\hline Task Title & Task Description \\
\hline Traffic light & $\begin{array}{l}\text { This task contains a page with a traffic light. The color of the traffic light, like the traffic lights on the streets, changes; The green light means go; Red } \\
\text { means do not go; and the yellow means to be prepared not to move and otherwise, you will lose points. }\end{array}$ \\
\hline \multirow[t]{2}{*}{ Magic door } & 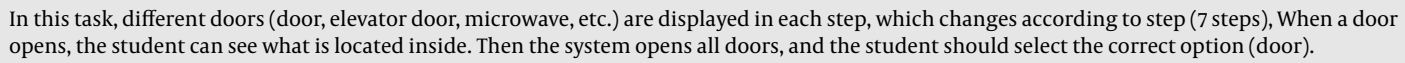 \\
\hline & $\begin{array}{l}\text { In this task, different doors (door, elevator door, microwave, etc.) are displayed in each step, which changes according to the step ( } 7 \mathrm{steps)} \text {. When a } \\
\text { door opens, the student can see what is located inside. Then, the system opens all doors and the student should select the correct option (door). }\end{array}$ \\
\hline Forest animals & $\begin{array}{l}\text { This task contains a page that has a margin that changes regularly, every few seconds, depending on the step of the task ( } 7 \text { steps), and several } \\
\text { animals appear in sequence on the page. One has to pay attention to the pictures of the animals on the screen, and if the color of the animal that } \\
\text { appears on the screen is similar to the color of the border of the screen, one should quickly click on the image. It starts with an animal and the } \\
\text { animals are added one by one. The student just has to compare the color of the last animal displayed with the color of the page border. }\end{array}$ \\
\hline \multirow[t]{2}{*}{ Toys } & $\begin{array}{l}\text { This task contains several images (target images), depending on the steps of the task ( } 7 \text { steps), which are located on the sides of the page (target } \\
\text { images), over time bubbles that are inside each of the children's toy images appear on the page that the person must click Tap images that are } \\
\text { similar to the target images on the sides of the screen. }\end{array}$ \\
\hline & $\begin{array}{l}\text { In this task, an image is placed under a microscope, and the person should decide according to the steps ( } 6 \text { steps), in each step according to the } \\
\text { abovementioned rules (similar to a few previous images), the image is similar to the previous the image or not. And if it was, tap on the image and } \\
\text { get points. }\end{array}$ \\
\hline \multirow[t]{2}{*}{ Microscope } & $\begin{array}{l}\text { In this task, an image is placed under a microscope, and the person should decide according to the steps ( } 6 \text { steps), in each step according to the } \\
\text { abovementioned rules (similar to a few previous images), the image is similar to the previous the image or not. And if it was, tap on the image and } \\
\text { get points. }\end{array}$ \\
\hline & $\begin{array}{l}\text { In this task, several colors will be displayed in order, depending on the steps of the task ( } 7 \text { steps) the person must listen to the colors expressed as } \\
\text { well as the order of their presentation, then a rainbow appears on the screen that the target color should be selected. The target color is located } \\
\text { between them, and the person must hit the rainbow according to the order in which the color is expressed. }\end{array}$ \\
\hline Table & $\begin{array}{l}\text { This task comprises several images (target images) depending on the step of the task ( } 7 \text { steps). Different colors and shapes are displayed and read on } \\
\text { the screen, respectively, then several different images appear on the page, including the target images. It is located, and the person must find and } \\
\text { tap those images according to the order, color, and shape of the presented images. }\end{array}$ \\
\hline
\end{tabular}

ance on their actions during learning. Therefore, two ideas of "Interaction" and "Feedback" form the heart of the principle of guided activity. The Guided Activity principle focuses mainly on manipulation and interactive dialogue (17).

\subsection{Program Validation}

To evaluate the content validity of the germane loadbased cognitive rehabilitation program, after the initial design, the images of the designed assignments, along with the scenarios developed for these assignments and additional explanations, were provided to the supervisors and consultants. The findings related to the dimensions, components, and sessions of the cognitive rehabilitation program to evaluate the content validity of the tool are shown in Table 3.

Based on the results, the minimum and maximum values of the relative content validity index (CVI) for each item or component of the program were 0.8 and 1 , respectively. The minimum and maximum content validity index (CVR) for each article or program component were 0.7 and 1, respectively. According to Hyrkas, AppelqvistSchmidlechner, and Oksa (2003), materials with a score higher than 0.79 are suitable, between 0.70 - 0.79 need revision and less than 0.7 are unacceptable and should be removed. Hence, in the present study, all materials are suit- able. Therefore, the germane load-based cognitive rehabilitation program has acceptable content validity for educational and clinical purposes.

\section{Discussion}

This study intended to design, develop, and evaluate a germane load-based cognitive rehabilitation program for students with special learning disabilities. To achieve this goal, first, we systematically reviewed the theoretical foundations and research background regarding the germane load. Moreover, experts' opinions were also obtained to design the intended rehabilitation program. The identified themes were summarized following the principles of germane load reinforcement, proposed by Mir and Moreno (2010), which includes the principle of multimedia principle, personalization, guided activity, feedback, and thinking. The principle of multimedia is based on the theory of dual encryption (15), which is based on the idea that different encryption systems (such as those used for words and images) reinforce each other. According to the CTML dual-channel hypothesis, humans have separate channels for processing visual and verbal materials (16). The personalization principle states that personalized information are more effective in learning (i.e. presented in a slang, friendly, and informal way), compared 
Table 3. Formal and Content Validity Indicators of the Dimensions and Components of The Rehabilitation Program

\begin{tabular}{|c|c|c|c|c|c|}
\hline Dimensions & Components of the Rehabilitation Program & Attributes & $\begin{array}{l}\text { Number of } \\
\text { Cases } 4 \text { and } 5\end{array}$ & C.V. R & C.V.I \\
\hline \multirow{3}{*}{ 1. Content } & \multirow{3}{*}{$\begin{array}{l}\text { Content includes } 9 \text { separate tasks of teaching children } \\
\text { that have different stages and levels of difficulty. }\end{array}$} & Being exclusive & 9 & 0.8 & 0.9 \\
\hline & & Clarity and transparency & 8 & 0.6 & 0.8 \\
\hline & & Simplicity and fluency & 9 & 0.8 & 0.9 \\
\hline \multirow{3}{*}{$\begin{array}{l}\text { 2. Learning } \\
\text { activity }\end{array}$} & \multirow{3}{*}{$\begin{array}{l}\text { The child actively interacts with each of the tasks and at } \\
\text { the same time acquires games and tasks based on external } \\
\text { and intrinsic awareness of the function of the } \\
\text { rehabilitation program and its effect on executive } \\
\text { functions and problem-solving in the field of learning } \\
\text { disabilities during various exercises. }\end{array}$} & Being exclusive & 8 & 0.6 & 0.8 \\
\hline & & Clarity and transparency & 9 & 0.8 & 0.9 \\
\hline & & Simplicity and fluency & 9 & 0.8 & 0.9 \\
\hline \multirow{3}{*}{ 3. Activation } & \multirow{3}{*}{$\begin{array}{l}\text { The instructor is an expert and master of the program } \\
\text { who is the main designer of the rehabilitation program } \\
\text { interventions and is responsible for training the } \\
\text { instructors following the executive capacities and the } \\
\text { level of development of the child. }\end{array}$} & Being exclusive & 9 & 0.8 & 0.9 \\
\hline & & Clarity and transparency & 9 & 0.8 & 0.9 \\
\hline & & Simplicity and fluency & 10 & 1 & 1 \\
\hline \multirow{3}{*}{$\begin{array}{l}\text { 4. Learning } \\
\text { materials } \\
\text { and } \\
\text { resources }\end{array}$} & \multirow{3}{*}{$\begin{array}{l}\text { Computers include a 9-task learning rehabilitation } \\
\text { package that includes all tasks with varying difficulty } \\
\text { levels, ranging from } 5 \text { to } 9 \text { difficulty, that are housed in a } \\
\text { computer program and are presented for each session } \\
\text { separately. }\end{array}$} & Being exclusive & 8 & 0.6 & 0.8 \\
\hline & & Clarity and transparency & 9 & 0.8 & 0.9 \\
\hline & & Simplicity and fluency & 9 & 0.8 & 0.9 \\
\hline \multirow{3}{*}{$\begin{array}{l}\text { 5. Learning } \\
\text { place }\end{array}$} & \multirow{3}{*}{$\begin{array}{l}\text { This program can be implemented in educational and } \\
\text { rehabilitation centers, medical centers, homes, and } \\
\text { schools. }\end{array}$} & Being exclusive & 9 & 0.8 & 0.9 \\
\hline & & Clarity and transparency & 9 & 0.8 & 0.9 \\
\hline & & Simplicity and fluency & 9 & 0.8 & 0.9 \\
\hline \multirow{3}{*}{$\begin{array}{l}\text { 6. Learning } \\
\text { time }\end{array}$} & \multirow{3}{*}{$\begin{array}{l}\text { The program is implemented in three parts. The first part, } \\
\text { which includes } 16 \text { sessions, contains teaching different } \\
\text { tasks in } 45 \text {-minute sessions. }\end{array}$} & Being exclusive & 9 & 0.8 & 0.9 \\
\hline & & Clarity and transparency & 9 & 0.8 & 0.9 \\
\hline & & Simplicity and fluency & 10 & 1 & 1 \\
\hline \multirow{3}{*}{ 7. Grouping } & \multirow{3}{*}{$\begin{array}{l}\text { The program runs individually to apply the principles of } \\
\text { germane load. }\end{array}$} & Being exclusive & 9 & 0.8 & 0.9 \\
\hline & & Clarity and transparency & 9 & 0.8 & 0.9 \\
\hline & & Simplicity and fluency & 10 & 1 & 1 \\
\hline \multirow{3}{*}{$\begin{array}{l}8 . \\
\text { assessment }\end{array}$} & \multirow{3}{*}{$\begin{array}{l}\text { In the first stage, the formal validity of the program was } \\
\text { reviewed by the members of the panel of experts and } \\
\text { their corrective comments were presented. }\end{array}$} & Being exclusive & 8 & 0.6 & 0.8 \\
\hline & & Clarity and transparency & 8 & 0.6 & 0.8 \\
\hline & & Simplicity and fluency & 9 & 0.8 & 0.9 \\
\hline \multirow{3}{*}{$\begin{array}{l}\text { 9. Abilities } \\
\text { and skills } \\
\text { acquired }\end{array}$} & \multirow{3}{*}{$\begin{array}{l}\text { Improvement of executive function skills in the field of } \\
\text { inhibition, cognitive flexibility, and working memory, } \\
\text { which is manifested in reducing the problems of children } \\
\text { with special learning disabilities in the field of memory. }\end{array}$} & Being exclusive & 9 & 0.8 & 0.9 \\
\hline & & Clarity and transparency & 10 & 1 & 1 \\
\hline & & Simplicity and fluency & 7 & 0.7 & 0.8 \\
\hline
\end{tabular}


to when presented in a serious and formal way (18). The feedback principle states that providing feedback during learning leads to cognitive processing for deeper understanding and that learning effectiveness depends on the relationship between the amount of feedback given and the learner's prior knowledge (15). The principle of thinking and reasoning is at the heart of germane's productive processing hypothesis and methods of increasing the load. This principle states that the learner's deep thinking and cognitive engagement with learning content lead to a deeper understanding of information (17). According to the cognitive load theory, reproductive processing increases the cognitive load, but the load that results from cognitive activities related to schema acquisition and automation. According to the CLT, the germane cognitive load is the only type of load that should be increased during learning because it "participates with learning rather than interfering with" (7). Accordingly, Mir and Moreno (2010) argued that the germane load is a cognitive processing that is useful for learning and refers to working memory resources that are directly allocated to learning-related information (intrinsic cognitive loading rather than external cognitive loading) (19). It can be achieved by challenging or encouraging the learner to try to understand the materials and involves the learner's deep understanding of the material through engagement in the cognitive processes of organization and coherence. Germane load, which is the key to build new schemas and automate schemas, serves this mechanism (7). Automating learned content not only can overcome the limitations of working memory but also can enhance learning. The educational designer should increase this type of cognitive load in the educational content s/he designs as much as possible (20). Thus, it can be argued that effective teaching methods encourage learners to invest in the relevant cognitive load to construct the design. This study also showed that the cognitive rehabilitation program has good content validity and is suitable for educational and clinical purposes. One of the most important steps in developing a standard educational or psychological program is gaining content validity. Research findings on the content validity of items or different parts of the program from the perspective of accreditation panel experts indicated their necessity as well as appropriateness (relevance, clarity, and simplicity). In other words, experts in their assessment believed that this program can be used for cognitive rehabilitation of children with learning disabilities. Cognitive rehabilitation is broadly defined as a systematic intervention designed to compensate for or improving the impact of cognitive or behavioral problems following a neurological injury or illness to maximize safety as well as enhancing daily functioning, independence, and quality of life. In- tervention can include cognitive, behavioral, or pharmacological approaches. In the present study, cognitive interventions were targeted. The effectiveness of cognitive rehabilitation in children with various disorders, such as learning disabilities, attention deficit hyperactivity disorder, and ABI is well-documented by several studies (9, 2123). Due to changes in cognitive skills and functional expectations that commonly occur in developing children, to ensure the effective interventions designed for children with neurological disorders, they should vary depending on age and developmental level. In the present study, the designed assignments had different levels of difficulty to increase the ability and motivation of learners to interact with these assignments, which in turn causes improved skills of students with disabilities. Designing educational materials to help people with learning disabilities is a complex and challenging task. However, we believe that having a deep understanding of principles necessary for designing supportive programs is of crucial importance for developing learning technologies. Our literature review revealed several educational principles on cognitive load theory that can be leveraged to help people with special learning disabilities (24). Students with learning disabilities often exhibit unique cognitive processing and features of working memory that may not be consistent with the principles of educational instructional design developed by ordinary learners. The distinguishing feature of students with special learning disabilities from other developmental disorders and academic problems is that these individuals show a much more severe Academic failure as academic material become more difficult and they pass from one educational level to another. This gap even is larger for students in high school age and above, which increases the risk of behavioral outbursts, severe academic failure, and dropout (25). Therefore, using cognitive rehabilitation programs is highly useful for avoiding academic failure and dropout of these students in the early years of education. The present study had limitations including only investigating students with learning disabilities in the second and third grades of elementary school. Hence, caution should be taken when generalizing the results to other students. Moreover, due to the Covid-19 outbreak, we faced challenges for following-up participants and even some participants refused to continue the study. Also, the duration of the follow-up period was reduced to avoid further dropouts of participants. Due to these limitations, it is recommended that the germane load-based cognitive rehabilitation program be considered as a comprehensive and approved program intended to improve the cognitive skills of students with special learning disabilities in educational and rehabilitation centers for special learning disabilities, as well as clinical and research work. 


\section{Footnotes}

Authors' Contribution: M, K.P,K. has contributed to study design, data collection, data analysis, drafting the manuscript writing, and critical revisions of the final manuscript. MH,A.M,A. has contributed to study design, data analysis, study supervision, drafting the manuscript writing, and critical revisions of the final manuscript.

Conflict of Interests: The authors declare no conflict of interest.

Ethical Approval: This study was approved by the Iran National Committee For Ethics in Biomedical Research (No.IR.KHU.REC.1398.058).

Funding/Support: This article is not any Funding and support.

\section{References}

1. Moll K, Kunze S, Neuhoff N, Bruder J, Schulte-Korne G. Specific learning disorder: prevalence and gender differences. PLoS One. 2014;9(7). e103537. doi: 10.1371/journal.pone.0103537. [PubMed: 25072465]. [PubMed Central: PMC4114805].

2. American Psychiatric Association. Diagnostic and statistical manual of mental disorders. 5th ed. Arlington: American Psychiatric Publishing; 2013.

3. Giofré D, Toffalini E, Altoè G, Cornoldi C. Intelligence measures as diagnostic tools for children with specific learning disabilities. LJMUResearch Online.

4. Taroyan NA, Nicolson RI, Fawcett AJ. Behavioural and neurophysiological correlates of dyslexia in the continuous performance task. Clin Neurophysiol. 2007;118(4):845-55. doi:10.1016/j.clinph.2006.11.273. [PubMed: 17317301].

5. Sweller J. In academe, what is learned, and how is it learned? Curr Dir Psychol Sci. 2015;24(3):190-4. doi: 10.1177/0963721415569570.

6. Sweller J. Working memory, long-term memory, and instructional design. I Appl Res Mem Cogn. 2016;5(4):360-7. doi: 10.1016/j.jarmac.2015.12.002.

7. Sweller J, van Merriënboer JJ, Paas F. Cognitive architecture and instructional design: 20 years later. Edu Psychol Rev. 2019;31(2):261-92. doi:10.1007/s10648-019-09465-5.

8. Cowan N. Working memory underpins cognitive development, learning, and education. Edu Psychol Rev. 2014;26(2):197-223.

9. Locascio G, Slomine BS. Cognitive rehabilitation for pediatric neurological disorders. Cambridge University Press; 2018.
10. Thorell LB, Lindqvist S, Bergman Nutley S, Bohlin G, Klingberg T. Training and transfer effects of executive functions in preschool children. Dev Sci. 2009;12(1):106-13. doi: 10.1111/j.1467-7687.2008.00745.x. [PubMed: 19120418].

11. Stephan WG, Stephan CW. Designing intercultural education and training programs: An evidence-based approach. Int J Intercult 2013;37(3):277-86. doi:10.1016/j.ijintrel.2012.05.001.

12. Lawshe $\mathrm{CH}$. A quantitative approach to content validity. Personnel Psychol.1975;28(4):563-75. doi: 10.1111/j.1744-6570.1975.tb01393.x.

13. Hyrkäs K, Appelqvist-Schmidlechner K, Oksa L. Validating an instrument for clinical supervision using an expert panel. Int J Nurs Stud. 2003;40(6):619-25. doi: 10.1016/s0020-7489(03)00036-1.

14. Moreno R, Mayer RE, Plass JL, Moreno R, Brunken R. Techniques that increase generative processing in multimedia learning: Open questions for cognitive load research. Cognitive Load Theory. Cambridge, NY: Cambridge University Press; 2010. p. 181-202.

15. Mayer R. The cambridge handbook of multimedia learning. 2nd Rev ed. Cambridge University Press; 2014.

16. Moreno R, Mayer R. Interactive multimodal learning environments. Educ Psychol Rev. 2007;19(3):309-26. doi:10.1007/s10648-007-9047-2.

17. Plass JL, Moreno R, Brünken R. Cognitive load theory. Cambridge university press; 2010

18. Kalyuga S. Instructional guidance: A cognitive load perspective. Charlotte, NC, USA: Information Age Publishing; 2016.

19. Tindall-Ford S, Agostinho S, Sweller J.Advances in cognitive load theory: rethinking teaching. 1st ed. Routledge; 2019.

20. Sweller J. Element interactivity and intrinsic, extraneous, and germane cognitive load. Edu Psychol Rev. 2010;22(2):123-38. doi 10.1007/s10648-010-9128-5.

21. Benedict RH, DeLuca J, Phillips G, LaRocca N, Hudson LD, Rudick $\mathrm{R}$, et al. Validity of the symbol digit modalities test as a cognition performance outcome measure for multiple sclerosis. Mult Scler 2017;23(5):721-33. doi: 10.1177/1352458517690821. [PubMed: 28206827]. [PubMed Central: PMC5405816].

22. Krasny- Pacini A, Limond J. Executive function interventions. New York University; 2020. Available from: https://www.cambridge.org/core.

23. Ylvisaker M, Adelson PD, Braga LW, Burnett SM, Glang A, Feeney $\mathrm{T}$, et al. Rehabilitation and ongoing support after pediatric TBI: twenty years of progress. J Head Trauma Rehabil. 2005;20(1):95-109. doi: 10.1097/00001199-200501000-00009. [PubMed: 15668573].

24. Seok S, DaCosta B, Kinsell C, Poggio JC, Meyen EL. Computer-mediated intersensory learning model for students with learning disabilities. TechTrends. 2010;54(2):63-71.

25. Swanson $\mathrm{H}$. Intelligence, working memory, and learning disabilities. In: Papadopoulos TC, Parrila RK, Kirby JR, editors. Cognition, intelligence, and achievement. Elsevier; 2015. doi: 10.1016/b978-0-12-4103887.00010-5. 
Table 2. Components Extracted from Document Analysis to Achieve Germane Load Components Based on Cognitive Load Principles

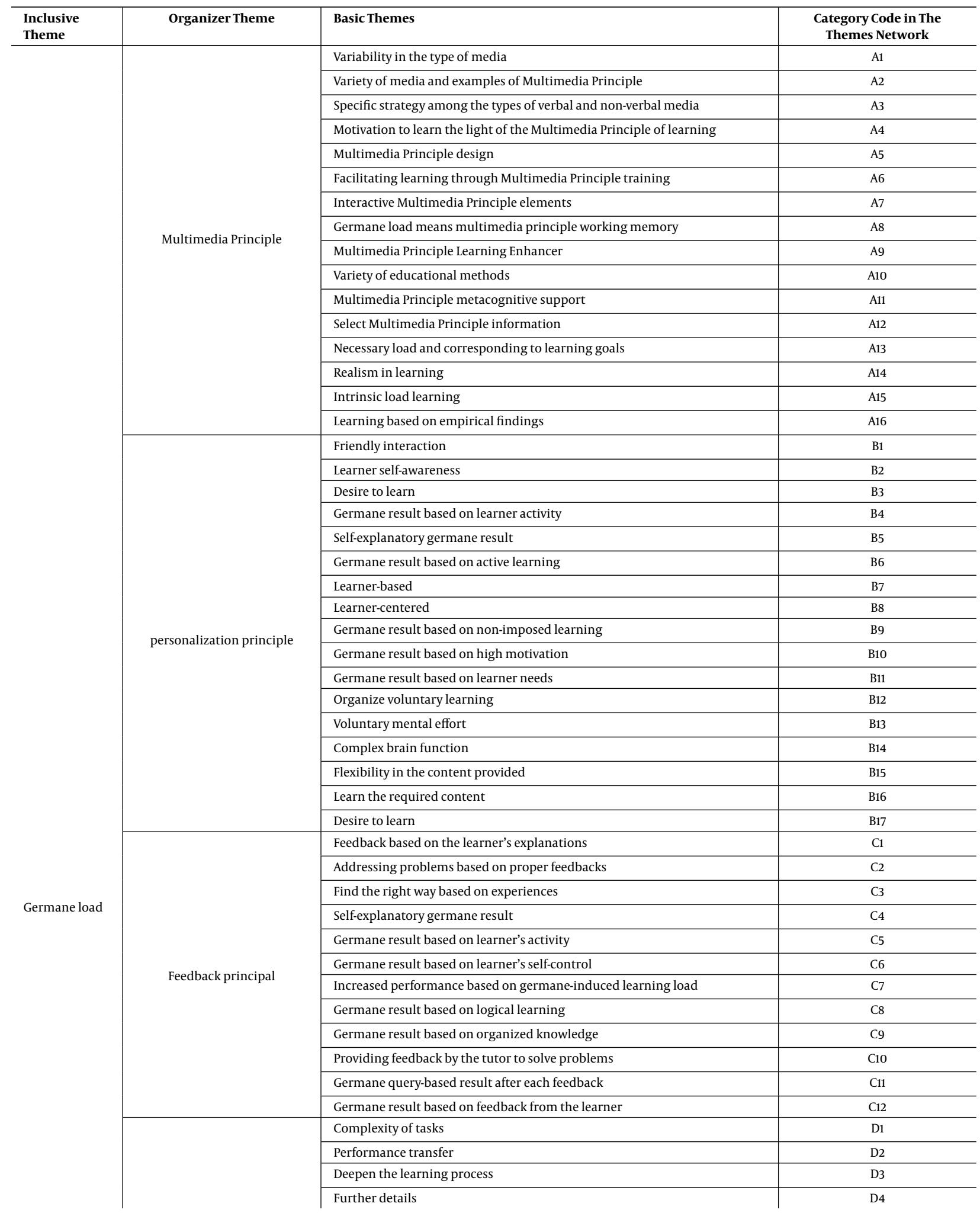




\begin{tabular}{|c|c|c|}
\hline & Differentiating true diagnosis from false & D5 \\
\hline & High motivation & D6 \\
\hline & Exploring & D7 \\
\hline & Intentional learning & D8 \\
\hline & Organized knowledge & D9 \\
\hline & Understanding the contents of the learning environment & D10 \\
\hline & Basic processing based on basic concepts & D11 \\
\hline & Strive to learn more & D12 \\
\hline & Content mental review & D13 \\
\hline & Content reminders & D14 \\
\hline & Practice and repeat content & D15 \\
\hline & Bring a reason to learn & D16 \\
\hline & Visualizing the learning process & D17 \\
\hline \multirow{8}{*}{ Guided Activity principal } & Formulating learning goals and selecting appropriate activities & E1 \\
\hline & $\begin{array}{l}\text { Establishing a logical connection between the components of learning } \\
\text { elements }\end{array}$ & E2 \\
\hline & Formulating appropriate achievement hypotheses for the learning goal & E3 \\
\hline & Learning based on multiple questions from peers & $\mathrm{E} 4$ \\
\hline & Problem-based learning & E5 \\
\hline & Guiding the learning process with the help of the teacher & E6 \\
\hline & Analysis of the interaction of learning elements and related activities & E7 \\
\hline & Understanding the interaction of learning elements and related activities & E8 \\
\hline
\end{tabular}


Table 4. Formal and Content Validity Indicators of Cognitive Rehabilitation Program Sessions

\begin{tabular}{|c|c|c|c|c|c|c|}
\hline Sessions & Content & Attributes & $\begin{array}{l}\text { Number } \\
\text { of Cases } \\
4 \text { and } 5\end{array}$ & C.V.R & C.V.I & Interpretation \\
\hline \multirow{3}{*}{ First Session } & \multirow{3}{*}{$\begin{array}{l}\text { Educating and providing information about } \\
\text { special learning disabilities for parents as well as } \\
\text { explaining the cognitive impairments caused by } \\
\text { this disorder, the expression of the cognitive } \\
\text { rehabilitation program, and the goals of the } \\
\text { program }\end{array}$} & Being exclusive & 10 & 1 & 1 & Appropriate \\
\hline & & $\begin{array}{l}\text { Clarity and } \\
\text { transparency }\end{array}$ & 9 & 0.8 & 0.9 & Appropriate \\
\hline & & $\begin{array}{l}\text { Simplicity and } \\
\text { fluency }\end{array}$ & 9 & 0.8 & 0.9 & Appropriate \\
\hline \multirow{3}{*}{ Second session } & \multirow{3}{*}{$\begin{array}{l}\text { Instructing parents about how to interact with } \\
\text { the child }\end{array}$} & Attributes & 8 & 0.7 & 0.8 & Appropriate \\
\hline & & Being exclusive & 9 & 0.8 & 0.9 & Appropriate \\
\hline & & $\begin{array}{l}\text { Clarity and } \\
\text { transparency }\end{array}$ & 7 & 0.7 & 0.8 & Appropriate \\
\hline \multirow[t]{2}{*}{ Third session } & \multirow{2}{*}{$\begin{array}{l}\text { Additional explanations and receiving feedback } \\
\text { from parents to strengthen the parent-child } \\
\text { interaction and filling the parent-specific } \\
\text { questionnaires. }\end{array}$} & Attributes & 9 & 0.8 & 0.9 & Appropriate \\
\hline & & Being exclusive & 10 & 1 & 1 & Appropriate \\
\hline \multirow{3}{*}{ Fourth session } & \multirow{3}{*}{$\begin{array}{l}\text { Describing executive functions for children and } \\
\text { teaching solutions to deal with executive } \\
\text { problems, working memory, inhibition, and } \\
\text { updating }\end{array}$} & $\begin{array}{l}\text { Clarity and } \\
\text { transparency }\end{array}$ & 10 & 1 & 1 & Appropriate \\
\hline & & $\begin{array}{l}\text { Simplicity and } \\
\text { fluency }\end{array}$ & 9 & 0.8 & 0.9 & Appropriate \\
\hline & & Attributes & 9 & 0.8 & 0.9 & Appropriate \\
\hline \multirow[b]{2}{*}{ Fifth session } & \multirow[b]{2}{*}{$\begin{array}{l}\text { Reviewing the previous session, teaching working } \\
\text { memory tasks (the first step), inhibition (task } 1 \text { of } \\
\text { the first step) }\end{array}$} & Being exclusive & 9 & 0.8 & 0.9 & Appropriate \\
\hline & & $\begin{array}{l}\text { Clarity and } \\
\text { transparency }\end{array}$ & 9 & 0.8 & 0.9 & Appropriate \\
\hline \multirow{3}{*}{ Sixth session } & \multirow{3}{*}{$\begin{array}{l}\text { Reviewing tasks related to previous sessions to } \\
\text { activate memory task training (task } 1 \text { of the } \\
\text { second step); Inhibition (the task of } 1 \text {, second and } \\
\text { third step) }\end{array}$} & Attributes & 9 & 0.8 & 0.9 & Appropriate \\
\hline & & Being exclusive & 10 & 1 & 1 & Appropriate \\
\hline & & $\begin{array}{l}\text { Clarity and } \\
\text { transparency }\end{array}$ & 9 & 0.8 & 0.9 & Appropriate \\
\hline \multirow{3}{*}{ Seventh session } & \multirow{3}{*}{$\begin{array}{l}\text { Reviewing tasks mentioned in previous sessions; } \\
\text { Updating the training (task } 1 \text { of the first step); } \\
\text { Inhibition (task } 1 \text { of the fourth step) }\end{array}$} & $\begin{array}{l}\text { Simplicity and } \\
\text { fluency }\end{array}$ & 9 & 0.8 & 0.9 & Appropriate \\
\hline & & Attributes & 9 & 0.8 & 0.9 & Appropriate \\
\hline & & Being exclusive & 9 & 0.8 & 0.9 & Appropriate \\
\hline \multirow{3}{*}{ Eighth session } & \multirow{3}{*}{$\begin{array}{l}\text { Reviewing tasks of the previous session; Active } \\
\text { memory training (task } 1 \text { of the third step); } \\
\text { Inhibition (task } 1 \text { of the fifth step); Update (task } 1 \\
\text { of the second step) }\end{array}$} & $\begin{array}{l}\text { Clarity and } \\
\text { transparency }\end{array}$ & 8 & 0.7 & 0.8 & Appropriate \\
\hline & & $\begin{array}{l}\text { Simplicity and } \\
\text { fluency }\end{array}$ & 8 & 0.7 & 0.8 & Appropriate \\
\hline & & Attributes & 10 & 1 & 1 & Appropriate \\
\hline \multirow{3}{*}{ Ninth session } & \multirow{3}{*}{$\begin{array}{l}\text { Reviewing tasks mentioned in previous sessions; } \\
\text { Active memory training (task } 1 \text { of the fourth and } \\
\text { fifth steps); Inhibition (task } 2 \text { of the first step); } \\
\text { Update (task } 1 \text { of the third step) }\end{array}$} & Being exclusive & 9 & 0.8 & 0.9 & Appropriate \\
\hline & & $\begin{array}{l}\text { Clarity and } \\
\text { transparency }\end{array}$ & 9 & 0.8 & 0.9 & Appropriate \\
\hline & & $\begin{array}{l}\text { Simplicity and } \\
\text { fluency }\end{array}$ & 9 & 0.8 & 0.9 & Appropriate \\
\hline
\end{tabular}




\begin{tabular}{|c|c|c|c|c|c|c|}
\hline \multirow{3}{*}{ Tenth session } & \multirow{3}{*}{$\begin{array}{l}\text { Reviewing tasks mentioned in previous sessions; } \\
\text { Active memory training (task } 2 \text { of the first and } \\
\text { second steps); Inhibition (task } 2 \text { of the second and } \\
\text { third steps); Update (task } 1 \text { of the fourth and fifth } \\
\text { steps) }\end{array}$} & Attributes & 9 & 0.8 & 0.9 & Appropriate \\
\hline & & Being exclusive & 8 & 0.7 & 0.8 & Appropriate \\
\hline & & $\begin{array}{l}\text { Clarity and } \\
\text { transparency }\end{array}$ & 9 & 0.8 & 0.9 & Appropriate \\
\hline \multirow{3}{*}{ Eleventh session } & \multirow{3}{*}{$\begin{array}{l}\text { Reviewing tasks mentioned in previous sessions; } \\
\text { Active memory training (task } 2 \text { of the third step); } \\
\text { Inhibition (task } 2 \text { of the fourth and fifth steps); } \\
\text { Update (task } 2 \text { of the first step) }\end{array}$} & $\begin{array}{l}\text { Simplicity and } \\
\text { fluency }\end{array}$ & 8 & 0.7 & 0.8 & Appropriate \\
\hline & & Attributes & 9 & 0.8 & 0.9 & Appropriate \\
\hline & & Being exclusive & 9 & 0.8 & 0.9 & Appropriate \\
\hline \multirow{3}{*}{ Twelfth session } & \multirow{3}{*}{$\begin{array}{l}\text { Reviewing tasks mentioned in previous sessions; } \\
\text { Active memory training (task } 2 \text { of the fourth and } \\
\text { fifth steps); Inhibition (task } 3 \text { of the first step); } \\
\text { Update (task } 2 \text { of the second step) }\end{array}$} & $\begin{array}{l}\text { Clarity and } \\
\text { transparency }\end{array}$ & 10 & 1 & 1 & Appropriate \\
\hline & & $\begin{array}{l}\text { Simplicity and } \\
\text { fluency }\end{array}$ & 8 & 0.7 & 0.8 & Appropriate \\
\hline & & Attributes & 8 & 0.7 & 0.8 & Appropriate \\
\hline \multirow{3}{*}{$\begin{array}{l}\text { Thirteenth } \\
\text { session }\end{array}$} & \multirow{3}{*}{$\begin{array}{l}\text { Reviewing tasks mentioned in previous sessions; } \\
\text { Active memory training (task } 3 \text { of the first step); } \\
\text { Inhibition (task } 3 \text { of the second and third steps); } \\
\text { Update (task } 2 \text { of the third and fourth steps) }\end{array}$} & Being exclusive & 8 & 0.7 & 0.8 & Appropriate \\
\hline & & $\begin{array}{l}\text { Clarity and } \\
\text { transparency }\end{array}$ & 9 & 0.8 & 0.9 & Appropriate \\
\hline & & $\begin{array}{l}\text { Simplicity and } \\
\text { fluency }\end{array}$ & 9 & 0.8 & 0.9 & Appropriate \\
\hline \multirow{3}{*}{$\begin{array}{l}\text { Fourteenth } \\
\text { session }\end{array}$} & \multirow{3}{*}{$\begin{array}{l}\text { Reviewing tasks mentioned in previous sessions; } \\
\text { Active memory training (task } 3 \text { of the second and } \\
\text { third steps); Inhibition (task } 3 \text { of the fourth step); } \\
\text { Update (task } 2 \text { of the fifth and sixth steps) }\end{array}$} & Attributes & 9 & 0.8 & 0.9 & Appropriate \\
\hline & & Being exclusive & 9 & 0.8 & 0.9 & Appropriate \\
\hline & & $\begin{array}{l}\text { Clarity and } \\
\text { transparency }\end{array}$ & 8 & 0.7 & 0.8 & Appropriate \\
\hline \multirow{3}{*}{ Fifteenth session } & \multirow{3}{*}{$\begin{array}{l}\text { Reviewing tasks mentioned in previous sessions; } \\
\text { Active memory training (task } 3 \text { of the fourth and } \\
\text { fifth steps); Inhibition (task } 3 \text { of the fifth step); } \\
\text { Update (task } 3 \text { of the first step) }\end{array}$} & $\begin{array}{l}\text { Simplicity and } \\
\text { fluency }\end{array}$ & 9 & 0.8 & 0.9 & Appropriate \\
\hline & & Attributes & 9 & 0.8 & 0.9 & Appropriate \\
\hline & & Being exclusive & 9 & 0.8 & 0.9 & Appropriate \\
\hline \multirow{3}{*}{ Sixteenth session } & \multirow{3}{*}{$\begin{array}{l}\text { Reviewing tasks mentioned in previous sessions; } \\
\text { Active memory training (all three tasks of); } \\
\text { Inhibition (task } 3 \text { of the sixth step); Update (task } 3 \\
\text { of the second and third steps) }\end{array}$} & $\begin{array}{l}\text { Clarity and } \\
\text { transparency }\end{array}$ & 9 & 0.8 & 0.9 & Appropriate \\
\hline & & $\begin{array}{l}\text { Simplicity and } \\
\text { fluency }\end{array}$ & 8 & 0.7 & 0.8 & Appropriate \\
\hline & & Attributes & 10 & 1 & 1 & Appropriate \\
\hline \multirow{3}{*}{$\begin{array}{l}\text { Seventeenth } \\
\text { session }\end{array}$} & \multirow{3}{*}{$\begin{array}{l}\text { Reviewing tasks mentioned in previous sessions; } \\
\text { Training of active memory tasks (the task, step); } \\
\text { Update (task } 3 \text { of the fourth and fifth steps) }\end{array}$} & Being exclusive & 9 & 0.8 & 0.9 & Appropriate \\
\hline & & $\begin{array}{l}\text { Clarity and } \\
\text { transparency }\end{array}$ & 9 & 0.8 & 0.9 & Appropriate \\
\hline & & $\begin{array}{l}\text { Simplicity and } \\
\text { fluency }\end{array}$ & 8 & 0.7 & 0.8 & Appropriate \\
\hline \multirow{3}{*}{$\begin{array}{l}\text { Eighteenth } \\
\text { session }\end{array}$} & \multirow{3}{*}{$\begin{array}{l}\text { Reviewing tasks mentioned in previous sessions; } \\
\text { Preparation for termination of treatment }\end{array}$} & Attributes & 9 & 0.8 & 0.9 & Appropriate \\
\hline & & Being exclusive & 9 & 0.8 & 0.9 & Appropriate \\
\hline & & $\begin{array}{l}\text { Clarity and } \\
\text { transparency }\end{array}$ & 8 & 0.7 & 0.8 & Appropriate \\
\hline
\end{tabular}

